\title{
Vital Signs Consciousness State
}

National Cancer Institute

\section{Source}

National Cancer Institute. Vital Signs Consciousness State. NCI Thesaurus. Code C119946.

The level of awareness of an organism during a vital signs assessment. 